Check for updates

Cite this: RSC Adv., 2021, 11, 18423

Received 24th February 2021

Accepted 8th May 2021

DOI: 10.1039/d1ra01496j

rsc.li/rsc-advances

\section{Thermosensitive alginate-gelatin-nitrogen-doped carbon dots scaffolds as potential injectable hydrogels for cartilage tissue engineering applications}

\begin{abstract}
Mojgan Ghanbari, Masoud Salavati-Niasari (D) * and Fatemeh Mohandes
Hybrid injectable and biodegradable hydrogels based on oxidized alginate/gelatin and containing nitrogendoped carbon dots (NCDs) as a reinforcement have been fabricated and crosslinked by 1-ethyl-3-(3dimethylaminopropyl) carbodiimide (EDC)/N-hydroxysuccinimide (NHS) as the chemical crosslinking agents in the hydrogel system. The idea of composite hydrogels relies on the assumption that they supply a microenvironment that is convenient for the exchange of nutrients via a porous structure and cell proliferation and have mechanical characteristics that approximately match natural tissue. The effect of the NCD content on the morphology structure, mechanical strength, swelling ratio, and biodegradation has been investigated. The results indicate that nanocomposite hydrogels containing a higher content of NCDs have smaller pore sizes and higher mechanical properties. The in vitro biodegradation and swelling behavior demonstrated that increasing the amount of NCDs up to $0.06 \%$ decreased the swelling ratio and weight loss of the hydrogels. The composite hydrogels are biocompatible, as verified by the MTT assay of MG-63 cells. The N-doped graphene quantum dots considerably affect degradation and interaction within the cells and hydrogels.
\end{abstract}

\section{Introduction}

Tissue engineering, which is a combination of life sciences and engineering procedures, provides a novel method to fabricate an architectural and practical biological replacement for fixing issues with the role of tissue within the usage of bioactive molecules, cells, and scaffolds. ${ }^{1-3}$ Hydrogels are one of the fundamental classes of biological materials used for the fabrication of scaffolds due to their comparable compositions and mechanical behavior to the extracellular matrix (ECM) of native cartilage tissues, high interaction with cells, and sufficient preparation of signals to maintain cell attachment, generation, and distinction., ${ }^{4,5}$ Hydrogels are 3D networks of cross-linked hydrophilic polymer chains, which absorb an amount of water more than a thousand times their dry mass, creating a jelly form that mimics the stem-cell niche. They are classified as synthetic and natural polymer-based hydrogels depending on their sources of raw material. Among them, natural hydrogels are designated as a promising subject of current investigation owing to their excellent biological characteristics. ${ }^{4,6}$ Injectable hydrogels are the latest research in this field. Besides this, they are non-toxic and easy to prepare. Hydrogel stability is a notable

Institute of Nano Science and Nano Technology, University of Kashan, P. O. Box. 87317-51167, Kashan, I. R. Iran. E-mail: salavati@kashanu.ac.ir; Fax: +98 31 55913201; Tel: +983155912383 benefit that can be prepared via different physical and chemical cross-linking procedures. ${ }^{7,8}$ Lately, the interplay of the in situ chemical cross-linking within macromolecules utilizing the Schiff base reaction between amine groups and aldehyde groups has been investigated because of multiple advantages, including reversibility, simplicity, easy control of reaction rate below moderate states, pH-sensitivity, biocompatibility, and avoidance of chemical crosslinkers. ${ }^{6,8}$ Hydrogels possess a great potential for cartilage repair because of their adjustable mechanical and chemical features. Therefore, a hydrogel scaffold can adjust cellular activity and bring about hyaline cartilage tissue regeneration., ${ }^{9,10}$

The sodium salt of alginic acid or alginate is a natural polysaccharide obtained from brown algae. Alginate is composed of alpha-t-guluronic acid and beta-D-mannuronic acid units, which are organized in poly(alpha---guluronate) (G blocks) and poly(beta-D-mannuronate) (M blocks). ${ }^{11}$ Since alginate has no adhesive ligands to activate cell attachment, a biopolymer, preferably a protein, must be combined to activate cell-material interplay. ${ }^{12}$ Gelatin is a biodegradable natural polymer, resulting from hydrolysis of collagen and cleavage of the triple helix. As collagen is a major component of the extracellular matrix (ECM), collagen, and gelatin are broadly applied in medical applications and tissue engineering. ${ }^{11,12}$ Gelatin can be combined with alginate via forming covalent bonds, ${ }^{13}$ by which alginate must be oxidized in a monitored way within 
potassium periodate $\left(\mathrm{KIO}_{4}\right)$ to create oxidized alginate (OA). The amino group residuum hydroxylysine or lysine of gelatin are covalently linked by the formed aldehydes of OA within the Schiff base reaction in the OA-GEL hydrogel. ${ }^{12}$ Since gelatin liquefies at normothermia temperatures, it is essential to crosslink it to generate a temperature-stable hydrogel. However, these hydrogels have low rheological properties, which limit their utilization. The addition of nanostructures in OA-GEL is an innovative advancement. It is hypothesized that uniform nanostructures can enhance intermolecular hydrophobic interactions by combining nanocomposite hydrogels and improve the rheological behavior of the hydrogels. Also, nanostructures can augment the OA-GEL network structure, providing enhanced thermal and mechanical characteristics. So far, couples of inorganic components have been considered, which incorporated metal oxide NPs, ${ }^{14}$ layered double hydroxides, ${ }^{15-17}$ carbon nanotubes, ${ }^{18}$ hydroxyapatite, ${ }^{19,20}$ graphene oxide, ${ }^{21,22}$ and clay minerals..$^{23-25}$

We have chosen materials that can simulate cartilage properties: oxidized alginate (OA), gelatin (GEL), and nitrogen-doped carbon dots (NCDs) as reinforcement. OA is a biodegradable hydrogel that can mimic the extracellular matrix (ECM). GEL is also biocompatible in medical procedures. NGO possesses several benefits, for instance, great biocompatibility, excellent environmental durability, inexpensive fabrication, and earthabundant raw materials. ${ }^{26}$

In this paper, hydrogel composites including, OA/GEL/NCDs were prepared by crosslinking the amino groups of GEL and the aldehyde groups of OA using $N$-hydroxysuccinimide (NHS) and 1-ethyl-3-(3-dimethylaminopropyl) carbodiimide (EDC) as chemical crosslinkers. We investigated the influence of the oxidation of alginate on the mechanical, physical, and morphological properties and the cytotoxicity of this hydrogel. We anticipate that this hydrogel creates a biodesign microenvironment with high biodegradation and biocompatibility for repairing cartilage tissue.

\section{Materials and methods}

\subsection{Materials}

Gelatin (microbiology grade), sodium alginate (molar mass 10 000-600 $000 \mathrm{~g} \mathrm{~mol}{ }^{-1}$ ), n-propanol, potassium periodate, ethyl alcohol, diphenyl ether, sodium chloride, acetone, ethylene glycol, 1-ethyl-3-(3-dimethylaminopropyl) carbodiimide (EDC), hexane, $N$-hydroxysuccinimide (NHS), $p$-phenylenediamine and silver nitrate were purchased from Merck company and utilized without further purification.

\subsection{Oxidation of alginate}

$2.01 \mathrm{~g}$ of sodium alginate and $11.2 \mathrm{~mL}$ of $n$-propanol were blended with DI-water in a $250 \mathrm{~mL}$ beaker to obtain $225 \mathrm{~mL}$ in total. The mixture was kept at $30^{\circ} \mathrm{C}$ in the dark under stirring (5 h) to dissolve the alginate completely. $1.16 \mathrm{~g}$ of potassium periodate $\left(\mathrm{KIO}_{4}\right)$ dispersed in $30 \mathrm{~mL}$ DI-water was combined with the alginate solution. The mixture was kept in the dark for $24 \mathrm{~h}$. The reaction was quenched by adding $1 \mathrm{~mL}$ of ethylene glycol (EG) and the mixture was agitated for another $30 \mathrm{~min}$. $6.5 \mathrm{~g}$ of sodium chloride $(\mathrm{NaCl})$ was dissolved in the above suspension to purify the polymer, which was next gradually added to $400 \mathrm{~mL}$ agitated ethyl alcohol. The white precipitate was dissolved in DI-water with $3.3 \mathrm{~g}$ of $\mathrm{NaCl}$ and reprecipitated in $250 \mathrm{~mL}$ ethyl alcohol. The precipitate was dissolved in DIwater again and precipitated in $200 \mathrm{~mL}$ acetone. Eventually, the precipitate was rinsed in agitated ethyl alcohol for $15 \mathrm{~min}$, refined, and dried at $25{ }^{\circ} \mathrm{C}^{27}$ The lack of periodate was controlled by combining $500 \mu \mathrm{L}$ fractions of the dialyzate to 500 $\mu \mathrm{L}$ of a $1 \%$ silver nitrate solution, assuring the nonexistence of any precipitate. ${ }^{28}$

\subsection{Fabrication of N-doped carbon dots (NCDs)}

$\mathrm{N}$-doped carbon dots were synthesized through the method reported by Wang et $a .^{26}$ In a typical procedure, $0.2 \mathrm{~g}$ of $p$ phenylenediamine (PPD) dissolved in $15 \mathrm{~mL}$ of diphenyl ether was heated at $200{ }^{\circ} \mathrm{C}$ for $3 \mathrm{~h}$ and next chilled to ambient temperature. The mixture was added to $50 \mathrm{~mL}$ of hexane to the precipitate. The total mixture was then centrifuged at $5000 \mathrm{rpm}$ for 10 minutes. After redoing the precipitation and centrifugation procedure three times, a brown powder was collected.

\subsection{Preparation of the OA/GEL/NCDs hydrogels}

$5 \mathrm{~mL}$ of $6 \mathrm{wt} \%$ of OA solution was agitated with $5 \mathrm{~mL}$ of $15 \mathrm{wt} \%$ of GEL at $37{ }^{\circ} \mathrm{C}$. The cross-linker, including a mixture of $0.1 \mathrm{~g}$ EDC and $0.05 \mathrm{~g}$ NHS, was added to the above solution. The first gelation was observed in $4-5 \mathrm{~s}$ and kept at $37^{\circ} \mathrm{C}$, resulting in the creation of a perfect gel after 2 min.

Different weight percentages of NCDs $(0.06 \%, 0.04 \%$, and $0.02 \%$ ) were added to the $5 \mathrm{~mL}$ of $6 \mathrm{wt} \%$ of OA solution and agitated for $5 \mathrm{~min}$. Next, $5 \mathrm{~mL}$ of $15 \mathrm{wt} \%$ of GEL was added to the suspension and stirred for another $5 \mathrm{~min}$. The final solutions were mixed for 2 min by adding EDC and NHS as crosslinker agents. The samples were freeze-dried for $24 \mathrm{~h}$.

\subsection{Swelling ratio and biodegradation}

The water absorption of the hydrogels was evaluated by the gravimetric technique. About $0.3 \mathrm{~g}\left(W_{0}\right)$ of the hydrogels was incubated in $10 \mathrm{~mL}$ PBS for $24 \mathrm{~h}$ to attain equilibrium swelling. The buoyant was removed and the swollen hydrogels were weighed $\left(W_{\mathrm{s}}\right)$. The swelling ratio (SR) was expressed by the following equation: ${ }^{19}$

$$
\operatorname{SR}(\%)=\frac{W_{\mathrm{s}}-W_{0}}{W_{0}} \times 100
$$

mass degradation/erosion degrees were additionally evaluated likewise at various periods up to 21 days. All tests were accomplished three times.

\subsection{Materials characterization}

Fourier transform infrared spectroscopy (Shimadzu Varian 4300 spectrophotometer) was utilized to investigate the chemical composition of oxidized alginate and the fabricated hydrogels by applying $\mathrm{KBr}$ pellets in the wavenumbers between $4000-$ 


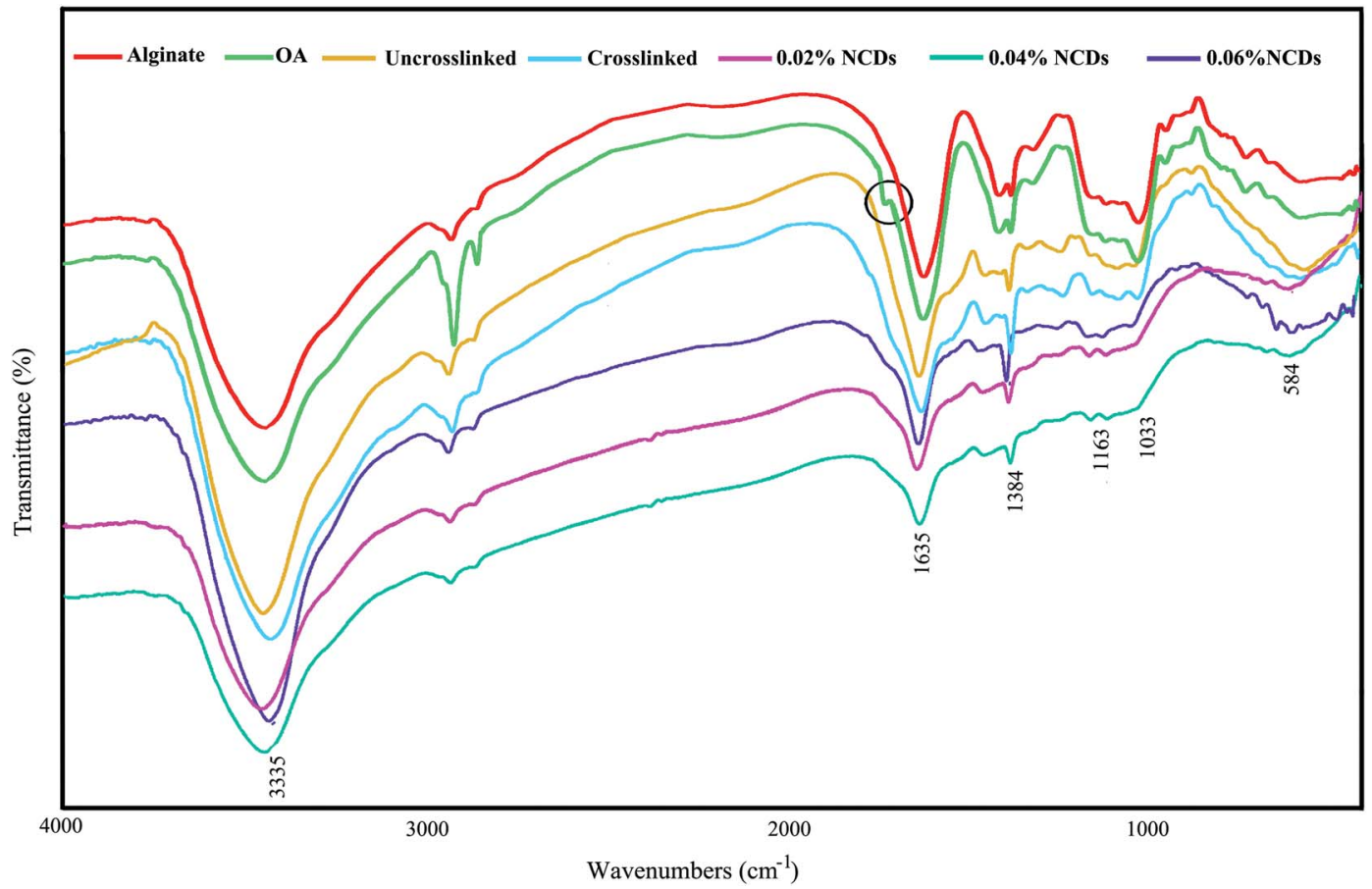

Fig. 1 FTIR spectra of alginate, oxidized alginate, and the hydrogels.
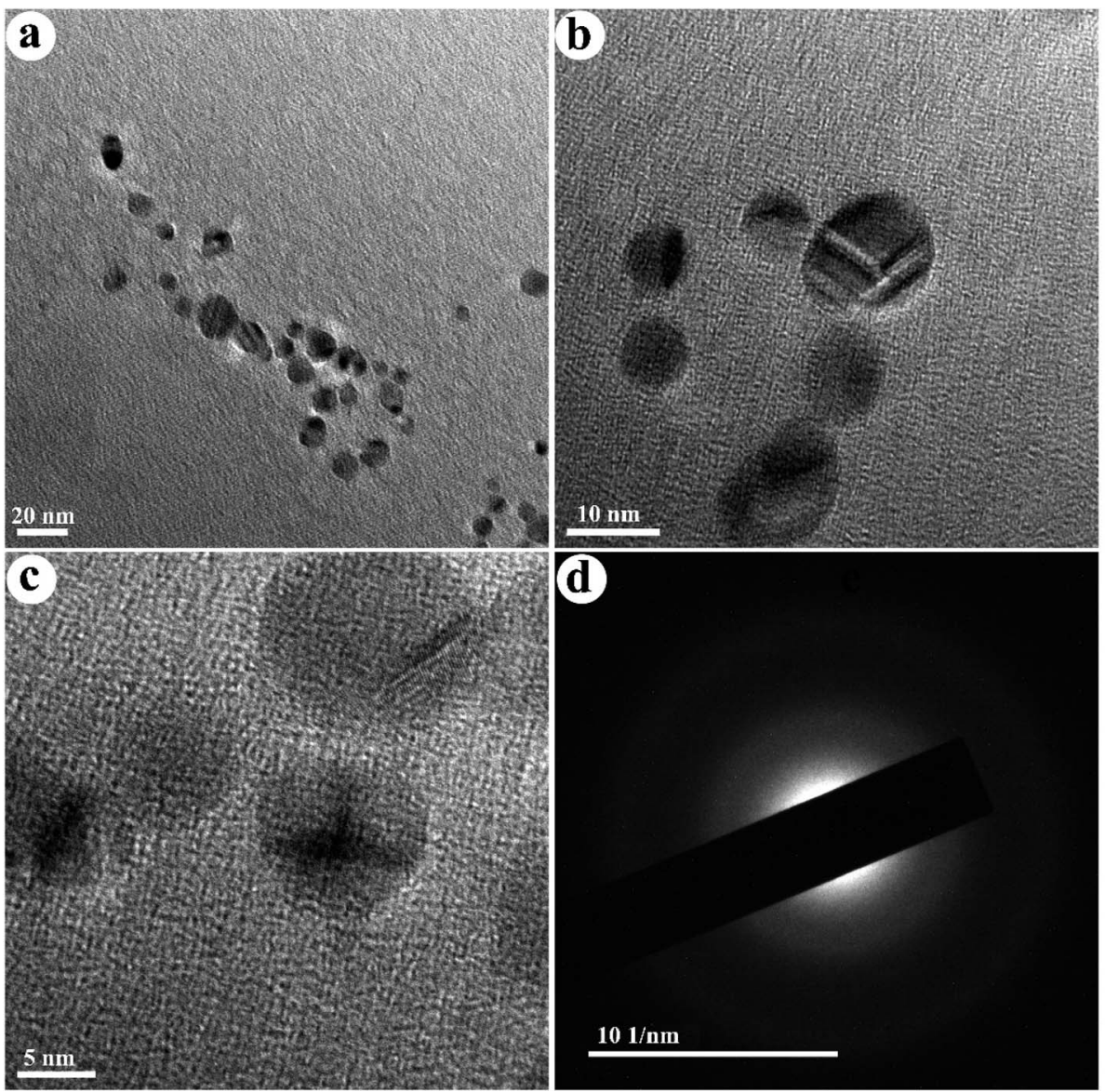

d)

Fig. $2(a-c)$ TEM images of NCDs and (d) SAED of NCDs. 
$400 \mathrm{~cm}^{-1}$. Field emission scanning electron microscopy (TESCAN MIRA 3 FE-SEM) was used to study the morphological and structural properties of the lyophilized hydrogels. The lyophilized hydrogels were cross-sectioned, coated with gold (Au), and detected by FE-SEM at an accelerating voltage of $15 \mathrm{kV}$. Highresolution transmission electron microscopy (EM 208, Philips HR-TEM with an accelerating voltage of $100 \mathrm{kV}$ ) was utilized to observe nitrogen-doped graphene quantum dots. A Physica MCR 300 Rheometer (Anton Paar Ltd., Austria) was utilized to measure the oscillatory rheological properties of the hydrogels.

\subsection{Mechanical properties}

A Physica MCR 300 Rheometer (Anton Paar Ltd., Austria) was used to measure the rheological attributes of the hydrogels utilizing a circular disk parallel plate with a diameter of $25 \mathrm{~mm}$ and a gap of $0.5 \mathrm{~mm}$. An amplitude sweep was conducted at a consistent angular frequency of $1 \mathrm{~Hz}$ to define the limit of linear viscoelasticity. The strain amplitude was kept at $0.1 \%$ during the test. The contributions of the liquid-like form (viscous modulus $\left(G^{\prime \prime}\right)$ ) and solid-like form (elastic modulus $\left(G^{\prime}\right)$ ) were noted through temperature sweeps from 20 to $50{ }^{\circ} \mathrm{C}$ at a speed of $1{ }^{\circ} \mathrm{C} \mathrm{min}^{-1}$ to assess the thermogelling attributes (angular frequency $=1 \mathrm{~Hz}$ ). Each following rheological test was conducted below the simulated physiological states (in $\mathrm{PBS} \mathrm{pH}$ $=7.4$ at $37{ }^{\circ} \mathrm{C}$ ), considering the possible utilization of the hydrogels. The oscillatory rheological determination as a function of time was conducted at a consistent frequency of $1 \mathrm{~Hz}$ to evaluate the time of gelation. The gel point or gelation time was specified as the time that the loss modulus and shear storage modulus were identical. ${ }^{29}$ The hydrogels were swollen for $1 \mathrm{~h}$ in $1 \mathrm{~mL}$ PBS and moved to the rheometer stage for performing crosslinked hydrogels. Next, frequency sweep analyses in the linear viscoelastic area were performed to determine the dynamic viscoelasticity at $37^{\circ} \mathrm{C}$ at a broad range of frequencies (0.1-100 Hz).

\subsection{In vitro biological assays}

The in vitro biocompatibility of the hydrogels was estimated by utilizing 3-(4,5-dimethylthiazol-2-yl)-2,5-diphenyltetrazolium bromide (MTT assay), which depends on the mitochondrial MTT reduction to produce an insoluble dark blue formazan. The samples were incubated in $1 \mathrm{~mL}$ of RPMI 1640 culture medium (Sigma-Aldrich) at $37{ }^{\circ} \mathrm{C}$ supplied by $10 \%(\mathrm{w} / \mathrm{w})$ fetal bovine serum (FBS) for 24 and $72 \mathrm{~h}$ to achieve the extracts of the
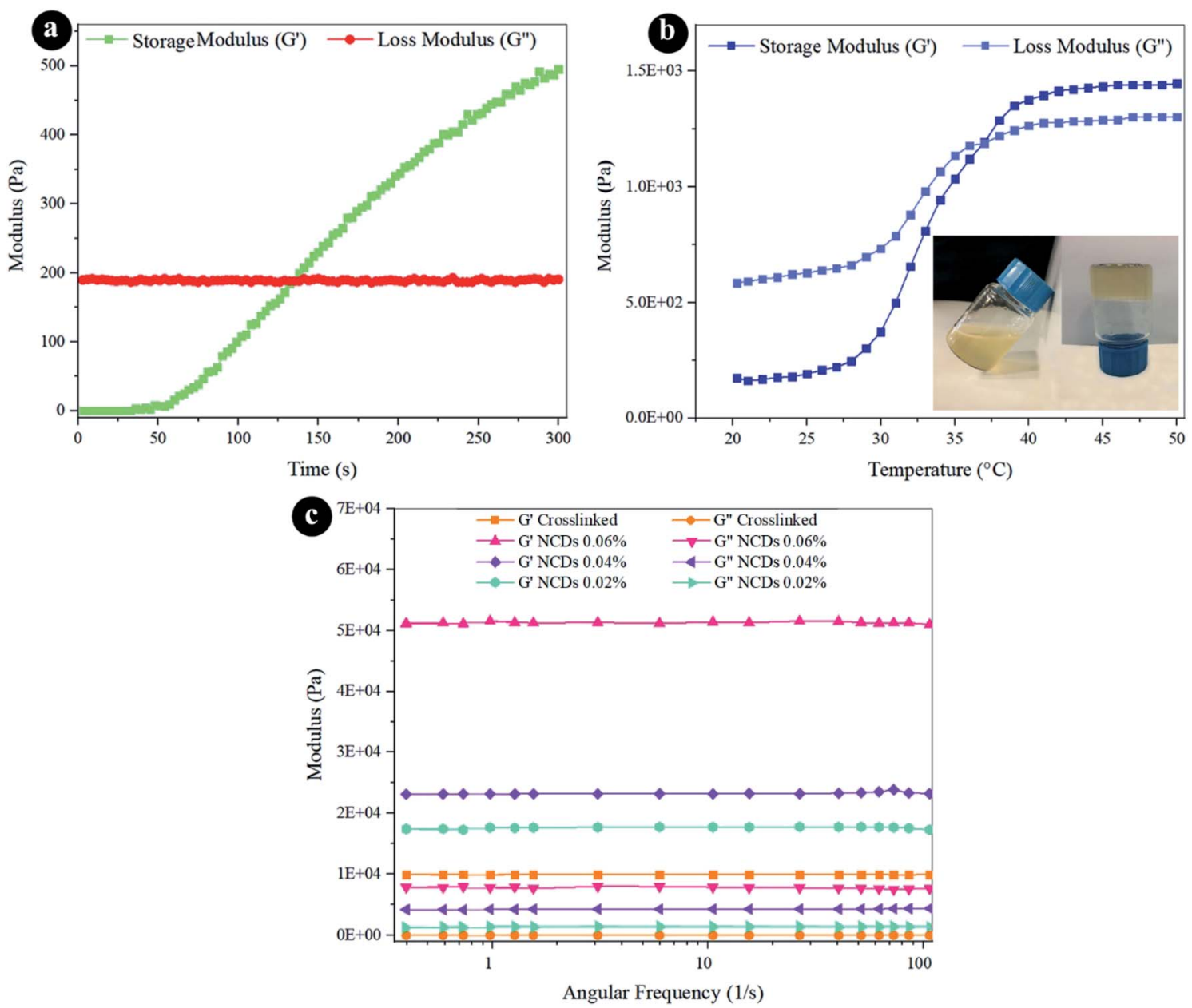

Fig. 3 Rheological properties of the hydrogels by (a) time sweep, (b) temperature sweep, and (c) frequency sweep. 
Table 1 Rheological properties of the hydrogels at $37{ }^{\circ} \mathrm{C}$ and a frequency of $1 \mathrm{~Hz}$

Average pore Sample $\quad$ Storage modulus $(\mathrm{Pa})$ Loss modulus $(\mathrm{Pa})$ size $(\mu \mathrm{m})$

\begin{tabular}{lccc}
\hline Crosslinked & $9929 \pm 24$ & $11.5 \pm 0.3$ & 161.1 \\
$0.02 \%$ NCDs & $17515 \pm 365$ & $1278 \pm 106$ & 116.9 \\
$0.04 \%$ NCDs & $23425 \pm 465$ & $4247 \pm 124$ & 115.3 \\
$0.06 \%$ NCDs & $51185 \pm 376$ & $7730 \pm 233$ & 102.5
\end{tabular}

as-dried hydrogels. The growth medium (RPMI and FBS) was utilized as the control under similar conditions. The MG63 cells were cultivated in 96-well plates at a density of $1 \times 10^{4}$ MG63 cells per sample. The growth medium was substituted by the hydrogels extract. The extract was removed after 24 h. $100 \mu \mathrm{L}$ of the MTT solution $\left(0.5 \mathrm{mg} \mathrm{mL}^{-1}\right)$ was added to all wells and incubated for another $4 \mathrm{~h}$ at $37{ }^{\circ} \mathrm{C}$. Then, the solution was eliminated and $100 \mu \mathrm{L}$ isopropanol was consequently added to liquefy the MTT crystals. The absorbance of the solutions was measured with a microplate spectrophotometer (Biotek Powerwave XS2, USA) at $570 \mathrm{~nm}$.
In order to study the architecture of the cell attached to the hydrogels, cross-sectional SEM images of the samples were recorded. The hydrogels were put in a Petri dish and incubated in the presence of DMEM and MG63 cells at $37^{\circ} \mathrm{C}$ for $24 \mathrm{~h}$. After incubating, the hydrogels were rinsed multiple times with PBS and set by $2.5 \%$ glutaraldehyde solution for $4 \mathrm{~h}$ at $4{ }^{\circ} \mathrm{C}$. Eventually, the samples were lyophilized and coated with $\mathrm{Au}$ for the FESEM surveys.

\section{Result and discussion}

A new faint peak was recognized at $1732 \mathrm{~cm}^{-1}$ in the spectrum of OA (Fig. 1), which was assigned to the symmetric vibration of the aldehyde group, showing that alginate is effectively oxidized via the $\mathrm{KIO}_{4}$. Besides, a decreased severity in the absorption was perceived at $815 \mathrm{~cm}^{-1}$ in the $\mathrm{OA}$. It might have led to the $\mathrm{C}-\mathrm{O}-\mathrm{C}$ decomposition on the alginate chains after the oxidation..$^{30}$ The spectra of the hydrogels show characteristic peak bands at $1635 \mathrm{~cm}^{-1}$ for the $\mathrm{C}=\mathrm{N}$ stretching vibrational mode, implying Schiff base reactions. The peak at $1635 \mathrm{~cm}^{-1}$ is wide due to overlaying with an amide-I group of the uncrosslinked GEL at $1632 \mathrm{~cm}^{-1} .^{30}$ The characteristic bands at 1035 and $1163 \mathrm{~cm}^{-1}$
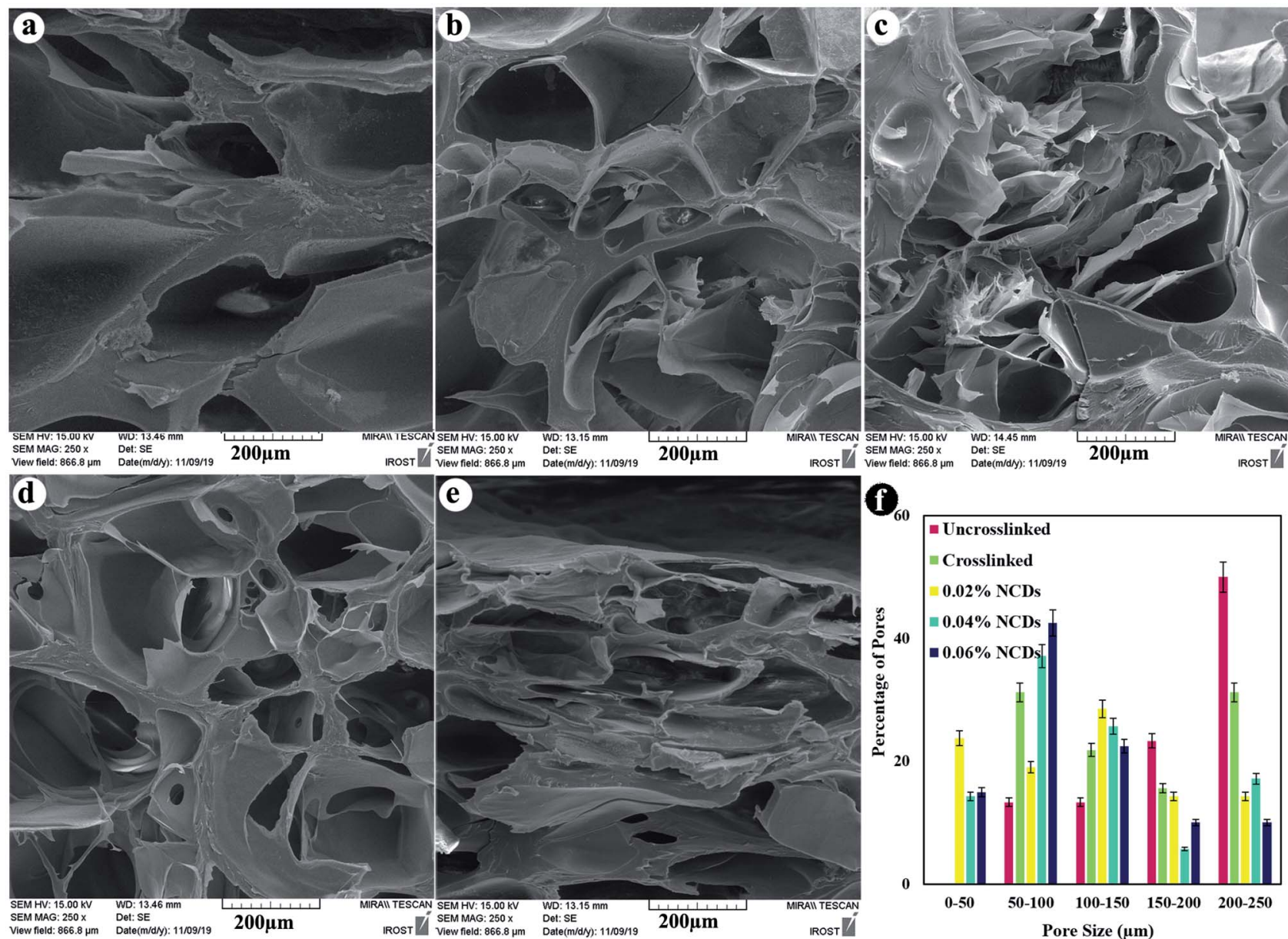

Fig. 4 Cross-sectional morphology of freeze-dried hydrogels (a) uncrosslinked, (b) crosslinked, (c) and containing $0.02 \%$ NCDs, (d) $0.04 \%$ NCDs, and (e) $0.06 \%$ NCDs. (f) The size distribution diagram of the samples. 
are designated as $\mathrm{C}-\mathrm{O}$, and $\mathrm{C}-\mathrm{O}-\mathrm{C}$ vibrational modes in the mannuronic and guluronic groups, respectively. The bands at 1635 and $1384 \mathrm{~cm}^{-1}$ are correlated to the carboxylic acid units of alginate. The broad peak at $3335 \mathrm{~cm}^{-1}$ is related to $-\mathrm{NH}$ and -OH stretching modes. The bonds of the NCDs overlap with the peaks of alginate and gelatin and are not detectable in the spectrum due to the low amounts of NCDs in the hydrogels.

The TEM images of the as-fabricated N-doped carbon dots (NCDs) are shown in Fig. 2. The NCDs with a particle size ranging from 6 to $14 \mathrm{~nm}$ and an average diameter of $\approx 9 \mathrm{~nm}$ are shown in this figure. Also, their distribution is monodisperse and regular. The SAED pattern presented in Fig. $2 d$ shows diffused rings, indicating the polycrystalline nature of the synthesized NCDs.

The gelation time is one of the most crucial factors of injectable hydrogels for their utilization. The long gelation time results in an irregular distribution of substances. The rheometer was selected to control the changes of loss modulus $\left(G^{\prime \prime}\right)$ and storage modulus $\left(G^{\prime}\right)$ with the time progression in the liquid to solid transition phase after adding crosslinkers. The preceding $G^{\prime}$ was less than $G^{\prime \prime}$, but the growth rate of $G^{\prime}$ was notably greater than $G^{\prime \prime}$. Wherever the $G^{\prime}$ crossed the $G^{\prime \prime}$, this time location was described as gelation time. As indicated in Fig. 3a, before gelation time, the $G^{\prime}$ was less than the $G^{\prime \prime}$, showing the liquid phase of the substance. After the gelation time, the $G^{\prime}$ was higher than the $G^{\prime \prime}$, which indicates that the hydrogel possesses a solid phase. The gelation time of the hydrogel is $120 \mathrm{~s}$, which is adequate for performing as an injectable hydrogel.

The thermosensitive behavior of the crosslinked hydrogel was distinguished by utilizing a temperature sweep analysis, as presented in Fig. 3b. $G^{\prime \prime}$ was higher than $G^{\prime}$ at lower temperatures, implying a fluid-like behavior. $G^{\prime}$ improved notably quicker than $G^{\prime \prime}$ during the heating process. At higher temperatures, $G^{\prime}$ became much bigger than $G^{\prime \prime}$, designating a jelly behavior. The intersection within $G^{\prime}$ and $G^{\prime \prime}$ at $37{ }^{\circ} \mathrm{C}$ was recognized as the gelation temperature. ${ }^{31}$ This implies that human body temperature can procure the alteration of the fluid to a gel.

The mechanical characteristics of the hydrogels perform the main role in their utilization, which concludes whether they can remain in a specific region and have an impact. $G^{\prime}$ indicates the strength of hydrogels to store elastic deformation energy and indicates the hardness of the hydrogels. A rheometer was applied to identify the alterations of $G^{\prime}$ and $G^{\prime \prime} v s$. angular frequency. As presented in Fig. 3c, the $G^{\prime}$ was greater than the $G^{\prime \prime}$ in the whole frequency spectrum, which indicates that the elasticity is dominant. It expressed that the frequency changes did not damage the composition of the hydrogels and that the hydrogels retained a solid phase. Also, the $G^{\prime}$ stayed constant amongst the entire frequency spectrum, confirming the character of the crosslinked hydrogels. $G^{\prime}$ developed quickly by increasing the quantity of NCDs, as illustrated in Table 1 and Fig. 3c. The $G^{\prime}$ of the hydrogel with $0.06 \%$ NCDs was five-fold greater than the $G^{\prime}$ of the crosslinked hydrogel. Expanding the amount of NCDs can lead to a greater crosslinking structure since it develops mechanical performance and the gelation through the existence of various reactive parts.

Cross-sectional FESEM images were taken to identify the lyophilized hydrogel microstructures (Fig. 4). The hydrogels exhibited a porous architecture due to the freeze-drying step, which produced pores as a result of the formation of ice crystals and is similar to other natural macromolecular hydrogels, with average pore sizes ranging from 102 to $161 \mu \mathrm{m}$. The interior morphology depended on the ratio of the NCDs contents. A greater ratio of NCDs leads to smaller pore diameters.

The swelling behavior of the samples was assessed in PBS at $37^{\circ} \mathrm{C}$. Fig. 5a revealed the swelling ratio of the hydrogels after $24 \mathrm{~h}$. The swelling capacity of the hydrogels diminished with an increment in NCDs content. The crosslinked hydrogel exhibits a swelling percentage of $1185 \%$ in $24 \mathrm{~h}$. The hydrogels containing $0.02 \%$ to $0.06 \%$ of NCDs revealed a swelling degree reducing from 983 to $813 \%$, respectively. A small reduction was observed in the swelling rate by enhancing the amount of NCDs because of the strong interplay between the NCDs and the hydrogel system.

Fig. 5b reveals the mass loss of hydrogels as a function of incubation time. The first weight increment was assigned to the swelling behavior of the hydrogel system, providing higher water absorption. The increase in the NCDs content notably reduced the degradation ratio of the hydrogel after 21 days. On day 21 , the residual percentage of $0.06 \%$ NCDs and $0.04 \%$ NCD
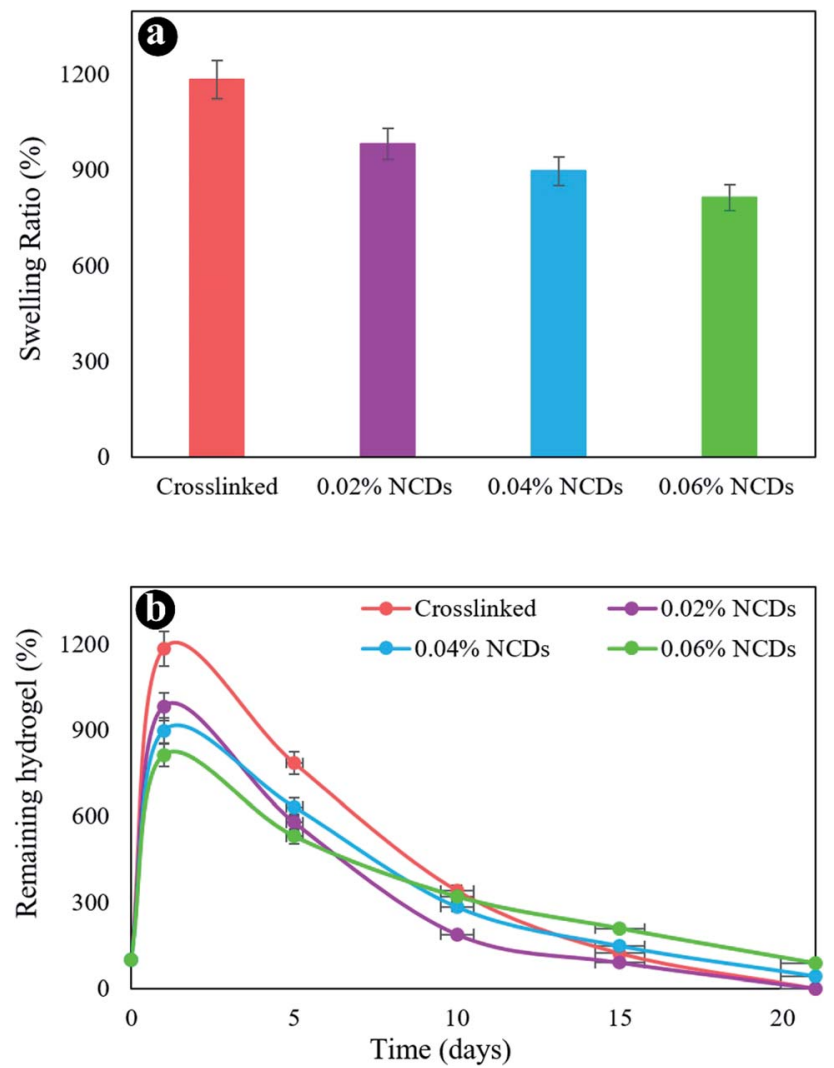

Fig. 5 (a) The swelling ratio of the hydrogels and (b) in vitro biodegradation after various incubation times in PBS at $37^{\circ} \mathrm{C}$. 

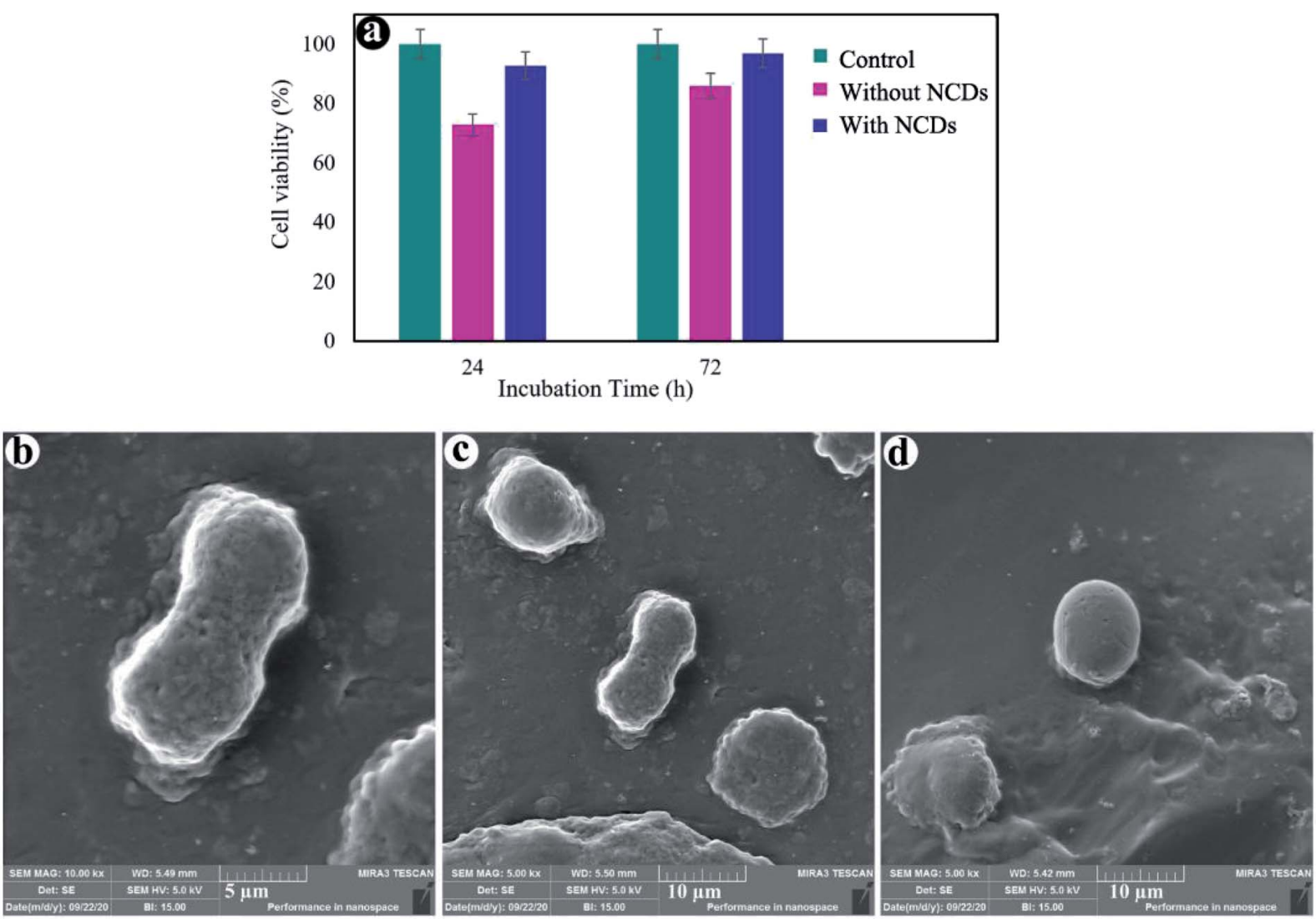

Fig. 6 Cell viability (a), FE-SEM images of the cell-cultured hydrogels with $0.06 \%$ NCDs (b and c) and without NCDs (d).

Table 2 Different scaffolds and their properties obtained for tissue engineering

\begin{tabular}{|c|c|c|c|c|}
\hline Materials & Cells & $\begin{array}{l}\text { Cell } \\
\text { culture }\end{array}$ & Special & Ref. \\
\hline Alginate-PVA-hydroxyapatite & Mouse calvaria (MC) 3T3-E1 & 14 days & $\begin{array}{l}\text { In vitro, viability }=\sim 77 \% \text { (after incubation), }>\sim 22 \% \text { for } \\
\text { only alginate, could maintain structure for at least } 14 \\
\text { days. Alginate hydroxyapatite had optimum } \\
\text { mechanical, rheological and biological characteristics. } \\
\text { PVA-hydroxyapatite modulates viscosity and thus } \\
\text { enhanced osteoconduction and viscosity }\end{array}$ & 32 \\
\hline $\begin{array}{l}\text { Alginate-PVA-hydroxyapatite- } \\
\text { collagen }\end{array}$ & $\begin{array}{l}\text { Mouse calvaria } \\
\text { (MC) 3T3-E1 }\end{array}$ & 10 days & $\begin{array}{l}\text { In vitro, initial viability }>98 \% \text {, collagen increases cell } \\
\text { adhesion and activity }\end{array}$ & 34 \\
\hline $\begin{array}{l}\mathrm{Na} \text { alginate-collagen or } \mathrm{Na} \\
\text { alginate-agarose }\end{array}$ & $\begin{array}{l}\text { Chondrocytes from the } \\
\text { articular cartilage of rats }\end{array}$ & $\begin{array}{l}14-21 \\
\text { days }\end{array}$ & $\begin{array}{l}\text { Na alginate-collagen possessed better mechanical } \\
\text { strength and bioactivity than other combinations }\end{array}$ & 35 \\
\hline Alginate-polycaprolactone & $\begin{array}{l}\text { Human nasal septum cartilage } \\
\text { chondrocytes }\end{array}$ & 7 days & $\begin{array}{l}\text { Osteogenic tissue engineering, viability }=\sim 94 \% \\
\text { (chondrocytes) } \sim 96 \% \text { (osteoblast), no observable } \\
\text { proliferation in chondrocytes }\end{array}$ & 36 \\
\hline Alginate-gelatin-fibrinogen & Glioma cells/stem cells & 21 days & $\begin{array}{l}\text { 3rd week showed accelerated growth mimicking the } \\
\text { tumor spreading and growth, cell viability }=86.92 \%\end{array}$ & 38 \\
\hline Sodium alginate-gelatin & Rat Schwann cell line (RSC96) & 14 days & $\begin{array}{l}\text { Viability }=\sim 93 \% \text { (post } 14 \text { days), printed structures } \\
\text { start degrading after } 14 \text { days }\end{array}$ & 39 \\
\hline Alginate-polycaprolactone & Chondrogenic cell ATDC5 & 21 days & $\begin{array}{l}\text { In vivo, } \sim 70 \text { viable cells, maintained integrity of the } \\
\text { PCL scaffold even after } 21 \text { days, composite mimics the } \\
\text { natural characteristics of cartilage }\end{array}$ & 40 \\
\hline Oxidized alginate-gelatin-NCDs & Osteosarcoma cell line MG63 & 1-3 days & $\begin{array}{l}\text { Viability }=97 \% \text { after } 3 \text { days, adding NCDs increases } \\
\text { cell viability, cell attachment, and storage modulus }\end{array}$ & $\begin{array}{l}\text { This } \\
\text { work }\end{array}$ \\
\hline
\end{tabular}


hydrogels was $86 \%$ and $43 \%$, respectively. By increasing the quantity of NCDs in the hydrogel network, hydrogel structures were demonstrated to be more stable than others. The presence of N-doped graphene quantum dots led to an increased crosslinking denseness, which affected several obvious features of the hydrogels, including enhanced mechanical properties, dense microstructures, slower weight loss, and less water uptake. We chose the nanocomposite hydrogel containing $0.06 \%$ NCDs as a perfect sample for additional research for consideration as a cartilage scaffold.

A perfect biomedical substance should not produce adverse reactions or release toxic products, and it could be assessed within in vitro cytotoxicity assays. The MTT assay is commonly acknowledged as a standard technique for determining the toxicity of materials. The effect of hydrogels with and without NCDs on the viability of MG63 cells was examined via an MTT assay after 24 and $72 \mathrm{~h}$ of incubation (Fig. 6a). The cell viability of the hydrogel without NCDs was $73 \%$ and $86 \%$ after 24 and $72 \mathrm{~h}$, respectively. Remarkably, the cell viability of the hydrogel containing $0.06 \%$ NCDs was improved after 1 and 3 day incubation (92.8\% and $97 \%$ ) due to the presence of NCDs in the hydrogel. The hydrogel with NCDs can be interiorized by the cells; hence, the MG63 cells can attach more effectively to the hydrogel matrices in the presence of the NCDs. The outcomes recommend that the hydrogel with $0.06 \%$ NCDs presents a guarantee as an injectable hydrogel that can be applied in cartilage regeneration or tissue engineering. Fig. $6 \mathrm{~b}-\mathrm{d}$ indicates the morphology of the MG63 cells on the surface of the hydrogel with and without NCDs after $24 \mathrm{~h}$ by scanning electron microscopy. Cell attachment and distribution on the scaffolds were investigated by SEM. The hydrogel containing $0.06 \%$ NCDs reveals higher cell adhesion. The cells attached to hydrogel with NCDs were observed to be greater in number, well distributed, and well-attached to the surface compared to the ones without NCDs. Cells seeded on the hydrogel without NCDs were spherical without any remarkable interplay within the hydrogel and cells. However, the NCDs hydrogel promoted cell adhesion, enabling the cells to be completely distributed on its surface and to attach to other cells.

Table 2 reviews the different hydrogels and their properties obtained for tissue engineering. As demonstrated in this table, OA/GEL/NCDs composite hydrogels are comparable with other composites reported in the literature.

\section{Conclusions}

Currently, several new substances and medical procedures are helping to repair damaged cartilage tissue. In summary, biodegradable and injectable OA/GEL hydrogels comprising different quantities of NCDs have been successfully fabricated and crosslinked by EDC/NHS as chemical crosslinkers. Variation in the amount of NCDs affected the mechanical properties, water uptake, biodegradation, and pore sizes. The results revealed that the hydrogel containing $0.06 \%$ NCDs possessed smaller pore sizes $(102 \mu \mathrm{m})$, lower water uptake (813\%), better mechanical properties, and less weight loss due to the strong interplay between NCDs and the hydrogel system. The temperature and time sweep showed that human body temperature could change fluids to gel and the nanocomposite hydrogels are suitable for injection in cartilage tissue regeneration. The in vitro biodegradation demonstrated that the crosslinked hydrogel (without NCDs) was more unstable than the one with a higher NCD content. The nanocomposite hydrogel showed excellent cell adhesion to MG63 cells and a cell viability of $>97 \%$ in the MTT assay. In general, the oxidized alginate/gelatin/NCDs nanocomposite hydrogels revealed excellent mechanical and stability properties by mimicking ECM biochemical markers, which could notably modify their biological performance in cartilage tissue engineering as injectable hydrogels.

\section{Conflicts of interest}

The authors declare that there are no conflicts of interest regarding the publication of this manuscript.

\section{Acknowledgements}

The authors are grateful to INSF (Iran National Science Foundation, 99017572 and 97017837) and the University of Kashan for funding this research by Grant No. 159271/09.

\section{References}

1 P. Nezhad-Mokhtari, M. Akrami-Hasan-Kohal and M. Ghorbani, Int. J. Biol. Macromol., 2020, 154, 198-205.

2 M. M. Islam, M. Shahruzzaman, S. Biswas, M. N. Sakib and T. U. Rashid, Bioact. Mater., 2020, 5, 164-183.

3 A. Pourjavadi, M. Doroudian, A. Ahadpour and S. Azari, Int. J. Biol. Macromol., 2019, 126, 310-317.

4 P. Nezhad-Mokhtari, M. Ghorbani, L. Roshangar and J. S. Rad, Int. J. Biol. Macromol., 2019, 139, 760-772.

5 C. Zhang, Q. Dong, K. Liang, D. Zhou, H. Yang, X. Liu, W. Xu, Y. Zhou and P. Xiao, Int. J. Biol. Macromol., 2018, 119, 270277.

6 S. Yan, X. Zhang, K. Zhang, H. Di, L. Feng, G. Li, J. Fang, L. Cui, X. Chen and J. Yin, J. Mater. Chem. B, 2016, 4, 947-961.

7 C. D. F. Moreira, S. M. Carvalho, H. S. Mansur and M. M. Pereira, Mater. Sci. Eng., C, 2016, 58, 1207-1216.

8 J. Xu, Y. Liu and S.-h. Hsu, Molecules, 2019, 24, 3005.

9 X. Li, Q. Xu, F. Alshehri, M. Zeng, D. Zhou, J. Li, G. Zhou and W. Wang, ACS Appl. Bio Mater., 2020, 3, 4756-4765.

10 B. J. Huang, J. C. Hu and K. A. Athanasiou, Biomaterials, 2016, 98, 1-22.

11 B. Sarker, D. G. Papageorgiou, R. Silva, T. Zehnder, F. Gul-ENoor, M. Bertmer, J. Kaschta, K. Chrissafis, R. Detsch and A. R. Boccaccini, J. Mater. Chem. B, 2014, 2, 1470-1482.

12 S. Schwarz, S. Kuth, T. Distler, C. Gögele, K. Stölzel, R. Detsch, A. R. Boccaccini and G. Schulze-Tanzil, Mater. Sci. Eng., C, 2020, 116, 111189.

13 B. Sarker, R. Singh, R. Silva, J. A. Roether, J. Kaschta, R. Detsch, D. W. Schubert, I. Cicha and A. R. Boccaccini, PLoS One, 2014, 9, e107952. 
14 P. Bhardwaj, S. Singh, V. Singh, S. Aggarwal and U. K. Mandal, Int. J. Polym. Mater., 2008, 57, 404-416.

15 E. Nourafkan, M. Asachi, H. Gao, G. Raza and D. Wen, J. Ind. Eng. Chem., 2017, 50, 57-71.

16 Z. Hu and G. Chen, Adv. Mater., 2014, 26, 5950-5956.

17 P. Fu, K. Xu, H. Song, G. Chen, J. Yang and Y. Niu, J. Mater. Chem., 2010, 20, 3869-3876.

18 L. Zhang, T. Tao and C. Li, Polymer, 2009, 50, 3835-3840.

19 F. M. Karvandian, N. Shafiei, F. Mohandes, B. Dolatyar, N. Zandi, B. Zeynali and A. Simchi, Mater. Chem. Phys., 2020, 242, 122515.

20 H. Gheysari, F. Mohandes, M. Mazaheri, B. Dolatyar, M. Askari and A. Simchi, Mar. Drugs, 2020, 18, 26.

21 J. Liu, G. Song, C. He and H. Wang, Macromol. Rapid Commun., 2013, 34, 1002-1007.

22 J. Fan, Z. Shi, M. Lian, H. Li and J. Yin, J. Mater. Chem. A, 2013, 1, 7433-7443.

23 O. Okay and W. Oppermann, Macromolecules, 2007, 40, 3378-3387.

24 G. Chen, D. Shen, M. Feng and M. Yang, Macromol. Rapid Commun., 2004, 25, 1121-1124.

25 S. C. Tjong, Mater. Sci. Eng., R, 2006, 53, 73-197.

26 H. Wang, C. Sun, X. Chen, Y. Zhang, V. L. Colvin, Q. Rice, J. Seo, S. Feng, S. Wang and W. W. Yu, Nanoscale, 2017, 9, 1909-1915.

27 A. D. Rogalsky, H. J. Kwon and P. Lee-Sullivan, J. Biomed. Mater. Res., Part A, 2011, 99, 367-375.

28 B. Balakrishnan and A. Jayakrishnan, Biomaterials, 2005, 26, 3941-3951.
29 D. Macaya, K. K. Ng and M. Spector, Adv. Funct. Mater., 2011, 21, 4788-4797.

30 L. Ma, W. Su, Y. Ran, X. Ma, Z. Yi, G. Chen, X. Chen, Z. Deng, Q. Tong and X. Wang, Int. J. Biol. Macromol., 2020, 165, 11641174.

31 L. Li, B. Yan, J. Yang, L. Chen and H. Zeng, Adv. Mater., 2015, 27, 1294-1299.

32 S. T. Bendtsen, S. P. Quinnell and M. Wei, J. Biomed. Mater. Res., Part A, 2017, 105, 1457-1468.

33 A. Kosik-Kozioł, M. Costantini, T. Bolek, K. Szöke, A. Barbetta, J. Brinchmann and W. Święszkowski, Biofabrication, 2017, 9, 044105.

34 S. T. Bendtsen and M. Wei, J. Biomed. Mater. Res., Part A, 2017, 105, 3262-3272.

35 X. Yang, Z. Lu, H. Wu, W. Li, L. Zheng and J. Zhao, Mater. Sci. Eng., C, 2018, 83, 195-201.

36 J.-H. Shim, J.-S. Lee, J. Y. Kim and D.-W. Cho, J. Micromech. Microeng., 2012, 22, 085014.

37 J. Park, S. J. Lee, H. Lee, S. A. Park and J. Y. Lee, Carbohydr. Polym., 2018, 196, 217-224.

38 X. Dai, C. Ma, Q. Lan and T. Xu, Biofabrication, 2016, 8, 045005.

39 X. Li, X. Wang, X. Wang, H. Chen, X. Zhang, L. Zhou and T. Xu, 3 Biotech, 2018, 8, 1-10.

40 A. D. Olubamiji, N. Zhu, T. Chang, C. K. Nwankwo, Z. Izadifar, A. Honaramooz, X. Chen and B. F. Eames, Tissue Eng., Part C, 2017, 23, 156-168. 